University of Nebraska - Lincoln

DigitalCommons@University of Nebraska - Lincoln

Faculty Publications, Department of Physics and Astronomy

Research Papers in Physics and Astronomy

1997

\title{
Molecular dynamics simulation of superionicity in neighborite, $\mathrm{NaMgF}_{3}$
}

\author{
L. X. Zhou \\ University of Nebraska - Lincoln \\ J. R. Hardy \\ University of Nebraska - Lincoln \\ H. Z. Cao \\ University of Nebraska - Lincoln
}

Follow this and additional works at: https://digitalcommons.unl.edu/physicsfacpub

Zhou, L. X.; Hardy, J. R.; and Cao, H. Z., "Molecular dynamics simulation of superionicity in neighborite, $\mathrm{NaMgF}_{3}$ " (1997). Faculty Publications, Department of Physics and Astronomy. 175.

https://digitalcommons.unl.edu/physicsfacpub/175

This Article is brought to you for free and open access by the Research Papers in Physics and Astronomy at DigitalCommons@University of Nebraska - Lincoln. It has been accepted for inclusion in Faculty Publications, Department of Physics and Astronomy by an authorized administrator of DigitalCommons@University of Nebraska - Lincoln. 


\section{Molecular dynamies simulation of superionicity in neighborite, $\mathrm{NaMgF}_{3}$}

\author{
L. X. Zhou, ${ }^{1}$ J. R. Hardy and H. Z. Cao \\ Department of Physics and Center for Electro-Optics, \\ University of Nebraska-Lincoln, Lincoln, NE 68588-0111
}

In the past, we have made extensive studies of halidebased perovskites [Flocken et al., 1990] which have largely been concerned with their phase diagrams well below their melting points, and have achieved a wide quantitative as well as qualitative success, using a combination of computer molecular dynamics (CMD) and parameter-free pair potentials derived by the GordonKim [Gordon and Kim, 1971] modified electron gas technique.

Most recently we have extended these to studies on superionic conduction in the fluorite $\mathrm{CaF}_{2}$ [Zhou et al., 1996-I] and the antifluorite $\mathrm{Li}_{2} \mathrm{O}$ [Zhou et al., 1996-II] and their isomorphs. Since this behavior is only manifest close to the melting temperature in these systems, it is not something we would have discovered previously should it also occur in halide-based perovskites, where it may have been observed experimentally [O'Keeffe and Bovin, 1979]. Since we have not previously studied a magnesium-based halide perovskite in detail, it seemed best to initiate any CMD based theoretical search for superionicity on $\mathrm{NaMgF}_{3}$ as part of an overall examination of the phase diagram of that system.

\section{Molecular Dynamics Investigation}

We thus carried out molecular dynamics simulations using our parameter-free Gordon-Kim /Gordon and Kim, 1971] potentials for rigid ions, using a periodic supercell with 320 ions $\left(64 \mathrm{Mg}^{2+}, 192 \mathrm{~F}^{-}, 64 \mathrm{Na}^{+}\right)$, heating from $0 \mathrm{~K}$ to $3000 \mathrm{~K}$ in $100 \mathrm{~K}$ steps, and averaging for $6 \mathrm{ps}$ after each heat pulse.

In order to establish the existence of superionicity, we monitored the $\vec{a} \vec{b}$ cross section of our supercell. At the onset of superionicity, we observe "linear disorder" in the $\mathrm{F}^{-}$sublattice coexisting with still ordered $\mathrm{Na}^{+}$ and $\mathrm{Mg}^{2+}$ sublattices, as can be seen in Figure 1, for which the temperature is $2880 \mathrm{~K}$. This behavior is seen for temperatures of $2880-2930 \mathrm{~K}$. Above $2930 \mathrm{~K}$ the cations also disorder and the crystal "melts." This "melting point" is much higher than the observed value of $1303 \mathrm{~K}$. Thus, these results are only qualitatively interesting in that they show clearly the onset of superionicity before melting. At higher temperatures, the $\mathrm{F}^{-}$sublattice becomes essentially disordered with ions clearly jumping into neighboring supercells. However, the cation sublattices remain intact.

In addition, the structural transformations reported at $1032 \mathrm{~K}$ and $1173 \mathrm{~K}$ [Chao et al., 1961] of which only 


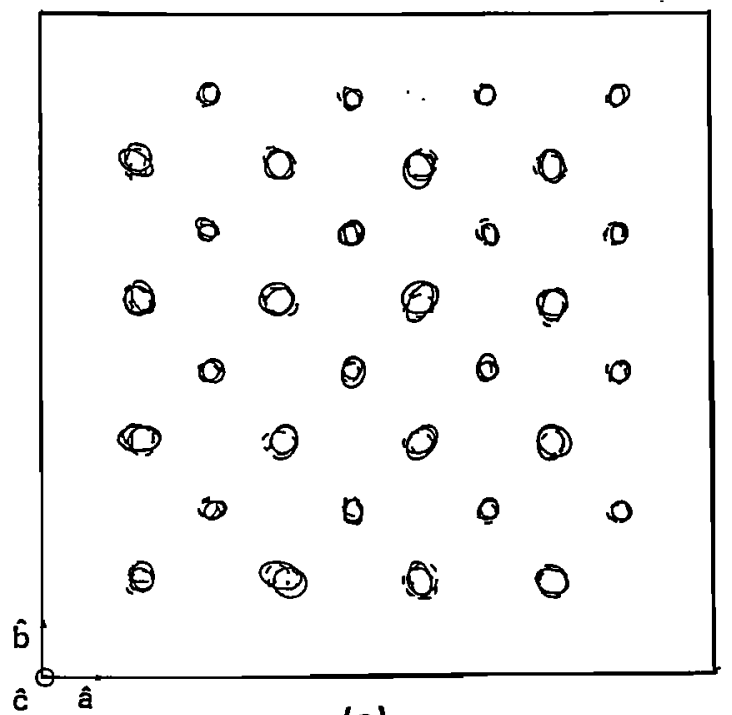

(a)

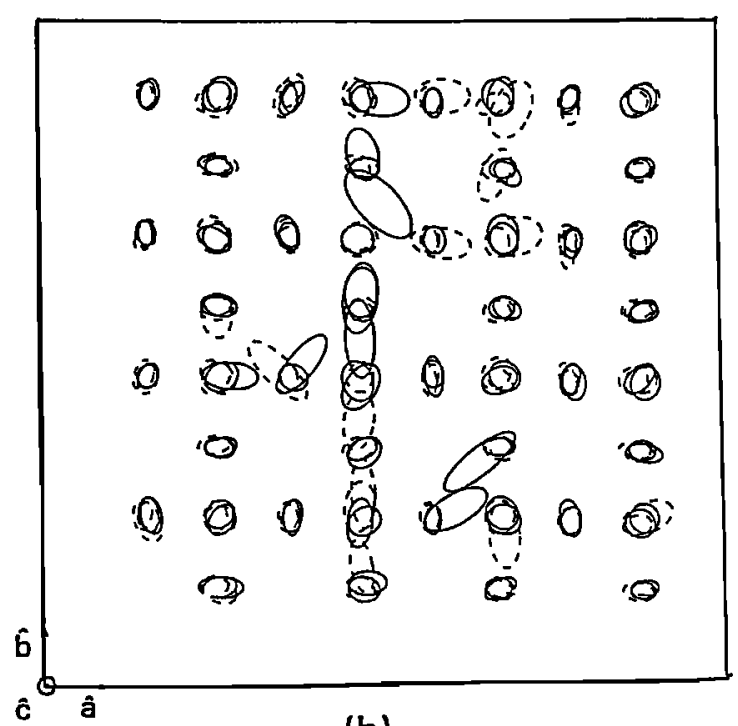

(b)

Figure 1. (a) Projections of the $\vec{a} \vec{b}$ cross sections of the four layers of $\mathrm{Na}^{+}$and $\mathrm{Mg}^{2+}$ ions in our 320 ion supercell on the basal plane. The temperature is $2880 \mathrm{~K}$ and the ellipsoids bound the region over which each ion moves to during the simulation. Clearly both sublattices are fully ordered. (b) Same projections for the $\mathrm{F}^{-}$ions - the large elongated and often displaced ellipsoids indicate superionic mobility. Both this Figure and Figure 2 are projections of all the layers on the $(x, y, 0)$ plane; the lowest layer corresponds to the solid lines and the others to broken lines.

the former is reproduced in very recent work, [Zhao et al., 1993-I; Zhao et al., 1993-II] are not reproduced either in temperature or in the observed change in symmetry. Specifically, we obtain only a single transition at $\sim 850-900 \mathrm{~K}$ to a near-trigonal phase, $\mathrm{a} \simeq \mathrm{b} \simeq \mathrm{c}=$ $3.6 \mathrm{~A}^{\circ}$ at $300 \mathrm{~K}$, c.f. $\simeq 3.8 \mathrm{~A}^{\circ}$ (expt.) /Chao et al., 1961; Zhao et al., 1993-I]. The most likely origin of these discrepancies is a defect in the simple Gordon-Kim model, most probably in the description of the $\mathrm{Mg}^{2+}-\mathrm{F}^{-}$interaction, since this bond may well be poorly described by a superposition of $\mathrm{Mg}^{2+}$ and $\mathrm{F}^{-}$charge distributions, owing to significant covalency. In this context, it is worth noting that $\mathrm{MgF}_{2}$ has the rutile rather than fluorite structure - something that is not favored by close packing of purely spherical ions [Megaw, 1973].

In order to obtain a clearer understanding, we ran a Quantum Chemistry GAUSSIAN 94 calculation [Frisch and Foresman, 1994] for the $\left[\mathrm{MgF}_{6}\right]^{4-}$ molecule and examined the Mulliken [Mulliken, 1955] populations of the orbitals. This gave a fluorine charge of -0.79 , implying an $\mathrm{Mg}$ charge of 1.37 in $\mathrm{NaMgF}_{3}$. Thus, as the simplest first approximation, we replaced the GordonKim charges by these new values without changing the Gordon-Kim short-range potentials. Since each outer closed shell contains eight electrons, the average change for the $\mathrm{F}^{-0.79}$ ions is only $\sim 2-3 \%$ and $\sim 5-8 \%$ for the $\mathrm{Mg}^{1.37}$ ions; furthermore, it is only the $\mathrm{F}^{-0.79}$ ions that have significant short-range interactions with units external to their octahedra.

We then repeated our molecular dynamics simulation using the same periodic supercell containing 320 ions $\left(64 \mathrm{Mg}^{+1.37}, 192 \mathrm{~F}^{-0.79}, 64 \mathrm{Na}^{+}\right)$, and heating from
$0 \mathrm{~K}$ to $2000 \mathrm{~K}$ in $100 \mathrm{~K}$ step averaging for $10 \mathrm{ps}$ after each heat pulse. This single change produces dramatically improved agreement with experiment. The onset temperature for superionicity is now $1330 \mathrm{~K}$, it persists at $1395 \mathrm{~K}$ and the "melting point" of the whole lattice is $\sim 1400 \mathrm{~K}$. In this case, we show in Figure 2 cross sections similar to those in Figure 1, but for a temperature of $1330 \mathrm{~K}$, demonstrating $\mathrm{F}^{-}$"chain disorder" coexisting with still ordered cation sublattices. Similar behavior is seen at a higher temperature $(1395 \mathrm{~K})$ prior to the final heat pulse which produces full disorder or "melting."

In Figure 3, we show the phase diagram below the superionic transition. Clearly the lowest temperature phase is orthorhombic in agreement with Mulliken (1955) and O'Keeffe and Bovin (1979). Also, the values of the axial lengths, $a, b$ and $c$ agree well with the experimental values $\left[a=3.79 \mathrm{~A}^{\circ}, b=3.88 \mathrm{~A}^{\circ}, \mathrm{c}=3.83 \mathrm{~A}^{\circ}\right.$ (expt.) (Chao et al., 1961; Zhao et al., 1993-I]: $\mathrm{a}=3.80 \mathrm{~A}^{\circ}, \mathrm{b}=$ $3.83 \mathrm{~A}^{\circ}, \mathrm{c}=3.83 \mathrm{~A}^{\circ}$ (theory), both for $\left.300 \mathrm{~K}\right]$. However, the onset of the transition away from the cubic phase, present above $1200 \mathrm{~K}$, appears to occur at $\sim 1175 \mathrm{~K}$ to what may be a transient near-tetragonal phase between $\sim 1175 \mathrm{~K}$ and $\sim 1030 \mathrm{~K}$. This assertion is obviously very tentative, since the changes in axial lengths are clearly within the limits of the statistical fluctuations at these temperatures. Below $1020 \mathrm{~K}$, the lattice is definitely orthorhombic, although the $\mathrm{a}$ and $\mathrm{b}$ axes switch below $\sim 450 \mathrm{~K}$. While these first two temperatures agree closely with the experimental values in Mulliken (1955) and O'Keeffe and Bovin (1979) have fairly definitively ruled out the existence of the tetragonal phase. As far 


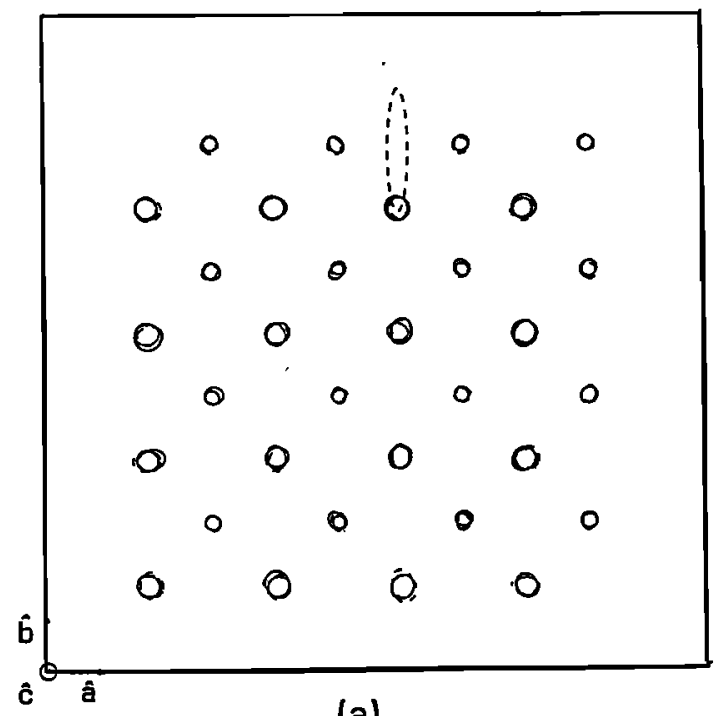

(a)

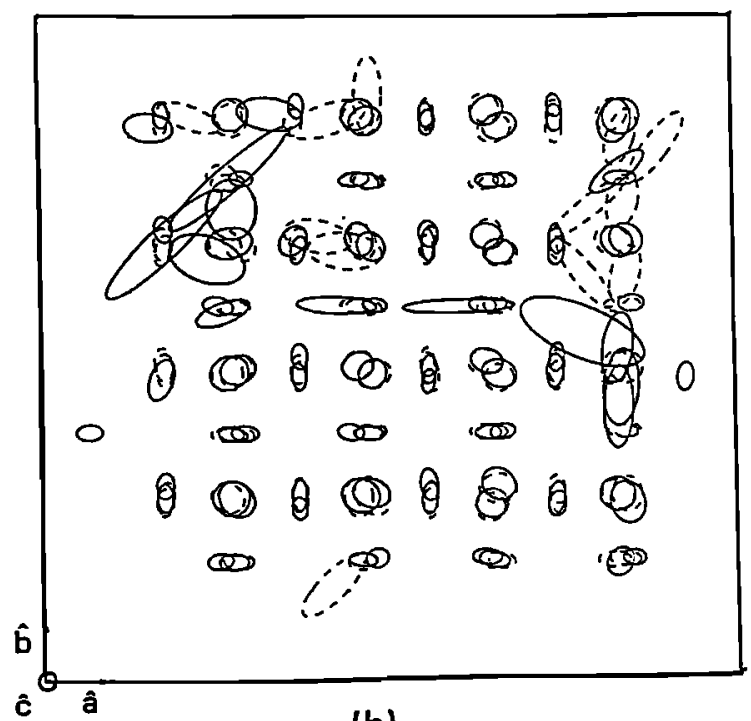

(b)

Figure 2. The same cross sections as those shown in Figure 1, but for $\mathrm{Mg}^{+1.37}$ and $\mathrm{F}^{-0.79}$ : (a) $\mathrm{Mg}^{+1.37}$ and $\mathrm{Na}^{+}$, (b) $\mathrm{F}^{-0.79}$. This time the temperature is $1330 \mathrm{~K}$. Again, we see clear superionicity in the $\mathrm{F}^{-0.79}$ sublattice, while the cation sublattices are still ordered. The single large ellipsoid in Figure 2(a) represents a transient excursion of a single $\mathrm{Na}^{+}$ion which disappears at $1395 \mathrm{~K}$.

as the lower temperature transition on which Mulliken (1955) and O'Keeffe and Bovin (1979) agree, there is good agreement with our calculated value of $\sim 1030 \mathrm{~K}$.

\section{Discussion}

That CMD may be showing a transient tetragonal phase suggests that such a phase might, depending on particular circumstances (e.g., growth conditions), be transiently metastable and be seen experimentally. Possibly this occurred for the work in Mulliken (1955). Whether the CMD "melting" temperature corresponds to that at which real melting would occur is questionable. However, since the most likely discrepancy for CMD with periodic boundary conditions is marked superheating, the fact that the superionic transition temperature is closely reproduced while "melting" occurs only $50-60^{\circ} \mathrm{K}$ higher (at $\mathrm{T}_{c} \sim 1400 \mathrm{~K}$, close to the ob-

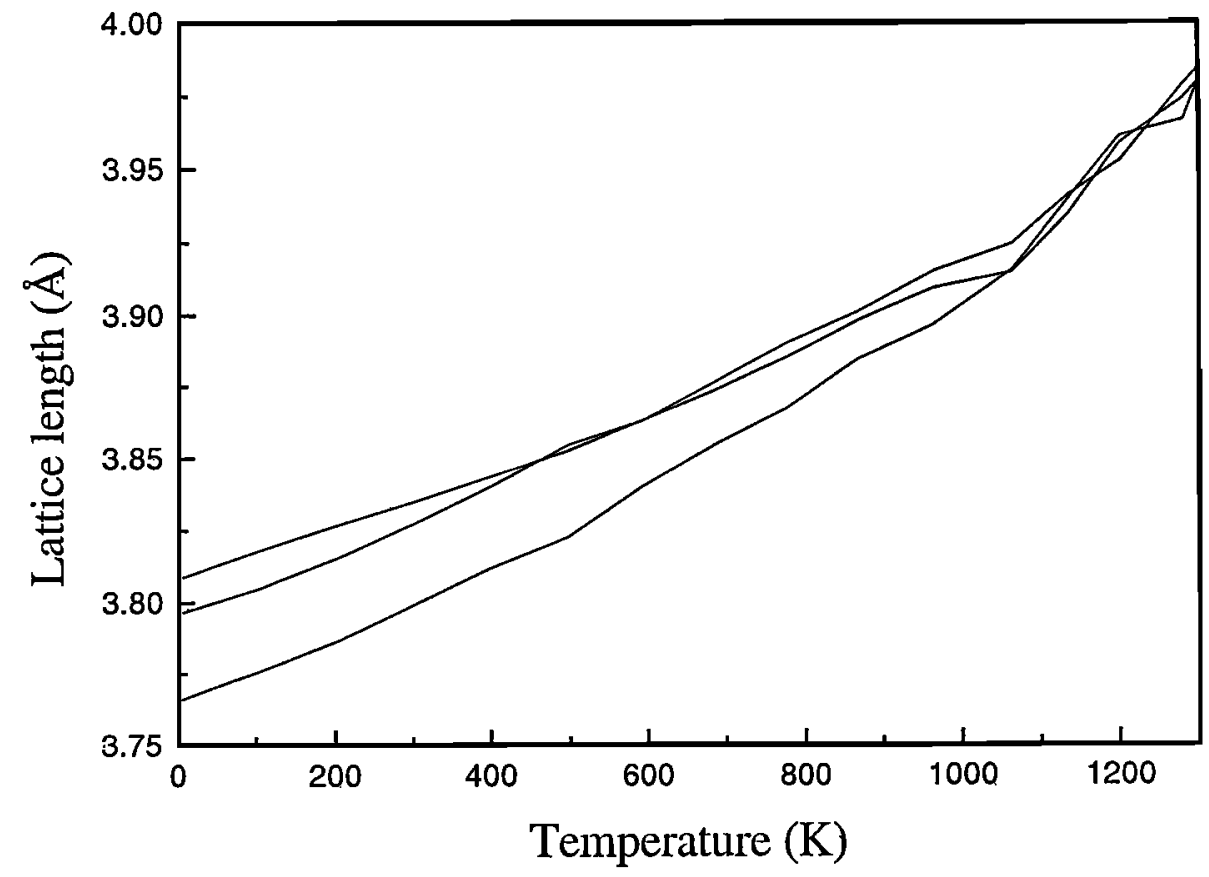

Figure 3. Axial lengths plotted as a function of temperature from our simulation of $\mathrm{Na}^{+} \mathrm{Mg}^{+1.37} \mathrm{~F}_{3}^{-0.79}$. 
served melting temperature) suggests that superheating, at least, is not present to any significant degree in the present simulation.

While our simple assumption of reduced ionicity in the $\mathrm{Mg}-\mathrm{F}$ bond can be questioned, we believe that the principal reason for its success is that it expands the $\mathrm{MgF}_{6}$ octahedra and thus the lattice (hence, the improved lattice constants). Apparently this improvement also gives more realistic "double-well potentials" for the $\mathrm{MgF}_{6}$ rotations so that they order in the manner described in Zhao et al. (1993-I) (equal antiphase rotations about two axes and an inphase rotation of different magnitude along the third).

Since any improvement over the fully ionic GordonKim potential must also achieve these aims, it is not unreasonable to argue that it, too, must predict the onset superionicity $\sim 50-100 \mathrm{~K}$ below the melting point. In addition, the fact that even the fully ionic potentials, which show superheating by almost a factor of two, also predict the onset of superionicity $50-100 \mathrm{~K}$ below melting, further supports the reality of this effect.

Acknowledgments. This work was supported by the U.S. Army Research Office under Grant No. DAAL-03-92G-0366.

\section{References}

Chao, E. C. T., H. T. Evans, Jr., B. J. Skinner, and C. Milton, Neighborite, $\mathrm{NaMgF}_{3}$, a new mineral from the Green River formation, South Ouray, Utah, The American Mineralogist, 46, 379-393, 1961.

Flocken, J. W., W. M. Mei, R. A. Guenther, J. R. Hardy, P. J. Edwardson, and L. L. Boyer, Ferroelectric phase transitions in $\mathrm{NaCa}$ halide perovskites, Phase Transitions, 20, 113-115, 1990.

Frisch, M. J., and J. B. Foresman, GAUSSIAN 94, CarnegiePittsburgh, Gaussian Inc.: Pittsburgh, PA 1994.

Gordon, R. G. and Y. S. Kim, Theory for the forces between closed-shell atoms and molecules, J. Chem. Phys., 56, 3122-3133, 1971.
Matsui, M. and G. D. Price, Simulation of the pre-melting behavior of $\mathrm{MgSiO}_{3}$ perovskite at high pressures and temperatures, Letters to Nature, 351, 735-737, 1991.

Megaw, H. D., Crystal Structures: A Working Approach, W. B. Saunders: Philadelphia 1973, p. 258.

Mulliken, R. S., Electron population analysis on LCAO-MO molecular wavefunctions, I, J. Chem. Phys., 23, 1833$1840,1955$.

O'Keeffe, M., and J. O. Bovin, Solid electrolyte behavior of $\mathrm{NaMgF}_{3}$ geophysical implication, Science, 100, 599-600, 1979.

Vocadlo, L., A. Patel and G. D. Price, Molecular dynamics: some recent developments in classical and quantum mechanical simulations of minerals, Mineralogical Magazine, 59, 597-605, 1995.

Wentzcovitch, R. M., J. L. Martins, and G. D. Price, $A b$ initio molecular dynamics with variable cell shape: Application to $\mathrm{MgSiO}_{3}$, Phys. Rev. Lett., 70, 3947-50, 1993.

Zhao, Y., D. J. Weidener, J. B. Parise, and D. E. Cox, Thermal expansion and structural distortion of perovskite-data for $\mathrm{NaMgF}_{3}$ perovskite, Part I, Phys. Earth Planet. Inter., 76, 1-16, 1993.

Zhao, Y., D. J. Weidener, J. B. Parise, and D. E. Cox, Critical phenomena and phase transition of perovskite, Part II, Phys. Earth Planet. Inter., 76, 17-34, 1993.

Zhou, L. X., J. R. Hardy, and H. Z. Cao, Dynamical simulations of superionicity in alkaline-earth halides, Solid State Commun., 98, 341-345, 1996.

Zhou, L. X., J. R. Hardy, and H. Z. Cao, Dynamical simulation of superionicity in antifluorites and in mixed systems, Solid State Commun., 99, 637-640, 1996.

L. Zhou, Department of Physics and Center for ElectroOptics, University of Nebraska-Lincoln, Lincoln, NE 685880111, USA Department of Physics, Xiamen University, China

J. Hardy, Department of Physics and Center for ElectroOptics, University of Nebraska-Lincoln, Lincoln, NE 685880111, USA

H. Cao, Department of Physics and Center for ElectroOptics, University of Nebraska-Lincoln, Lincoln, NE 685880111, USA

(Received June 25, 1996; revised December 2, 1996; accepted February 12, 1997.) 